\title{
FURTHER ASPECTS OF AGGRESSIVE BEHAVIOR INDUCED BY SUSTAINED HIGH DOSE OF THEOPHYLLINE IN RATS*
}

\author{
Toshiie SAKATA and Hideaki FUCHIMOTO \\ The First Department of Internal Medicine, Faculty of Medicine, \\ Kyushu University, Fukuoka, Japan
}

Accepted April 9, 1973

\begin{abstract}
Sustained injection with a high dose of theophylline increased aggressiveness in rats in both behavioral ratings and paired fighting. In the latter test, $50 \%$ of theophyllinized pairs took the fighting position following a hand-clap and the $75 \%$ of treated rats were dominant over control partners. In the open field test, the theophyllinized rat discharged fewer boluses, but there was no change in ambulatory activity. The present results support the finding in our previous study that demonstrated the production of affective aggression with the chronic treatment of theophylline.
\end{abstract}

A previous study (1) has shown that the repeated administration of large doses of theophylline induced affective aggressive behaviors in rats. The purpose of the present report is to extend this study. In order to achieve a quantification of this form of aggressiveness, the procedures of the aggressiveness rating, the reflexive fighting test and the open field test were utilized.

\section{MATERIALS AND METHODS}

Male albino rats of the Wistar strain, 95-110 days of age were used at the beginning of the experiment. 26 subjects were randomly divided into 14 as the theophylline group and 12 as the saline control. The dose of theophylline used was five $\mathrm{mg}$ in one $\mathrm{ml}$ saline per $100 \mathrm{~g}$ body wt. and the same volume of saline was injected into the controls. During the experiment, each subject was injected i.p. twice daily for 20 days at a two hr interval. All subjects were restricted to $20 \%$ of their usual diet, but had free access to water.

The open field, aggressiveness rating and the reflexive fighting tests, were performed to accomplish measurement of aggressiveness in rats. Each test was carried out once before and once after the course of injections. These three tests were done three, two and one day before and 17,18 and 20 days after the injection, respectively.

A more detailed description of the method is described in a previous report (1).

Procedures were as follow: Open field lesting-The area used consisted of a round field $60 \mathrm{~cm}$ in diameter with a sheet-tin wall $47 \mathrm{~cm}$ in height, painted flat gray except for thin red concentric circles and radial lines which divided the floor into 19 blocks. The field was illuminated by a 30-w fiuorescent circle lamp with a shade from a height of $80 \mathrm{~cm}$ to diffuse the illumination as uniformly as possible over the field. Each subject was placed individually into the center circle of the field for a three minute period. Since Whimbey

* Supported in part by the Pharmacopsychiatry Research Foundation, and Scientific Research grant No. 777196 from the Ministry of Education, Japan. 
(2) demonstrated that scores on the first day of open field testing do not reflect ones from day two onward, three trials were administered on the test day before the treatment and one trial on the day after. As for scores obtained before the treatment, only the scores on the third trial were used on data analysis. The following records were made for each trial: the total number of blocks entered (ambulation), frequency of rearing, preening and grooming, and the number of boluses dropped in the field throughout the testing.

Aggressiveness ratings-Animals were rated for aggressiveness by a modified Nauta's emotionality scale (3). The behaviors rated included: 1) reaction to visual presentation of a clamp; 2) reaction to a light tap on the back; 3) reaction to a light touch on the head; 4) response to a puff of air delivered over the entire dorsal surface of the body; 5) resistance to capturc; 6) amount and kind of vocalization during testing. For the first five measures, animals were given a score from zero to four, and fron zero to two for measure six.

Reflexive fighting test-Subjects were randomly assigned to pairs in cach group. Paired animals were placed in an experimental chamber similar to that described by Bernstein and Moyer (4). The test cage used was $30 \times 25 \times 25 \mathrm{~cm}$ with a grid floor of $1 / 8 \mathrm{in}$. stainless steel bars spaced $1.0 \mathrm{~cm}$ apart, and wired for scrambled shock. The two ends and the top were made of wood, and painted gray inside. The back side of the apparatus was constructed of a shect of milk glass, while the front side was a one-way vision screen which made it possible to observe animals without the distraction of movements by observers. The apparalus was illuminated by a 20 -w bulb located behind the milk-glass wall. An opaque guillotine type door could be lowered to divide the test cage into two compartments 15 and $12 \mathrm{~cm}$ long with the smaller compartment to the front of the cage. Thus, one of the paired rats could be placed in the smaller compartment and presented to another rat by raising the opaque door. After $45 \mathrm{sec}$ had elapsed, a hand-clap was made, and then the duration of fights was recorded for 15 seconds regarding reaction to an auditory stimulus (adaptation period). The fighting responses were defined as a stereotyped sparring position. After the adaptation period, a two $\mathrm{mA}$ shock for two sec was delivered through the grid floor with a two min interval between each shock, for a total of three shock trials. The observers recorded both the number and the duration of fighting responses (first shock period). Following this shock period, the same two mA shock was delivered continuously until the fighting responses mentioned above occurred, whereupon the shock was immediately terminated, A latency-to-fight measure was obtained. For $10 \mathrm{~min}$ after this shock, the duration of fighting responses was recorded in the same way (second shock period). After this testing, dominancy between the theophyllinized and the control animals was delermined by attack responses in which an animal completely jumped upon an opponent's belly.

\section{RESULTS}

Since two out of 14 in the theophyllinized group died from the toxic effects of the drug in the early stages of the treatment, the data for these two were discarded. 


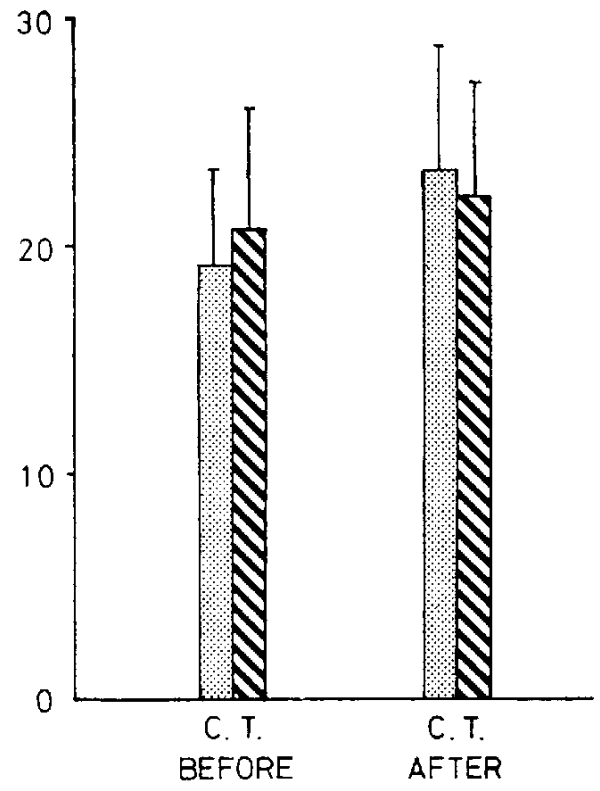

Fio. 1. Effect of theophylline on ambulatory activity in the open field test.

Sessions before and after the treatment are plotted along the abscissa. The mean number of blocks traversed during testing is plotted along the ordinate. In this and in the succeeding double panel figures, hatched and dotted columns represent the theophylline (T.) and the saline control groups (C.), respectively. Vertical bar represents standard error.
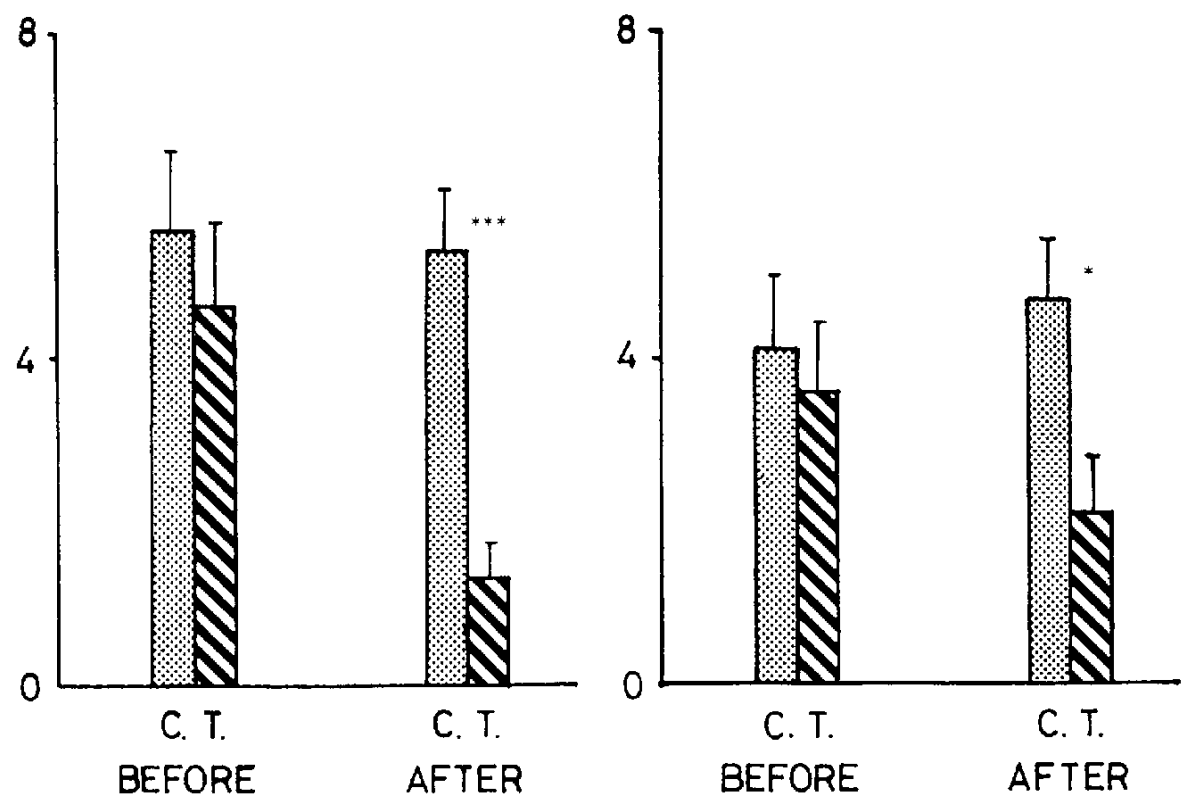

FIC. 2. Effect of theophylline on defecation (left hand panel) and rearing measures (right hand panei) in the open field test.

Sessions before and after the treatment are plotted along the abscissa. The mean number of boluses dropped in the field throughout the testing is plotted alung the ordinate on the left hand panel and the mean frequency of rearing during testing is plotted along the ordinate on the right hand panel. An asterisk indicates statistical significance in respect to the control group at a $5 \%$ level and triple asterisk does so at a $0.1 \%$ level. 

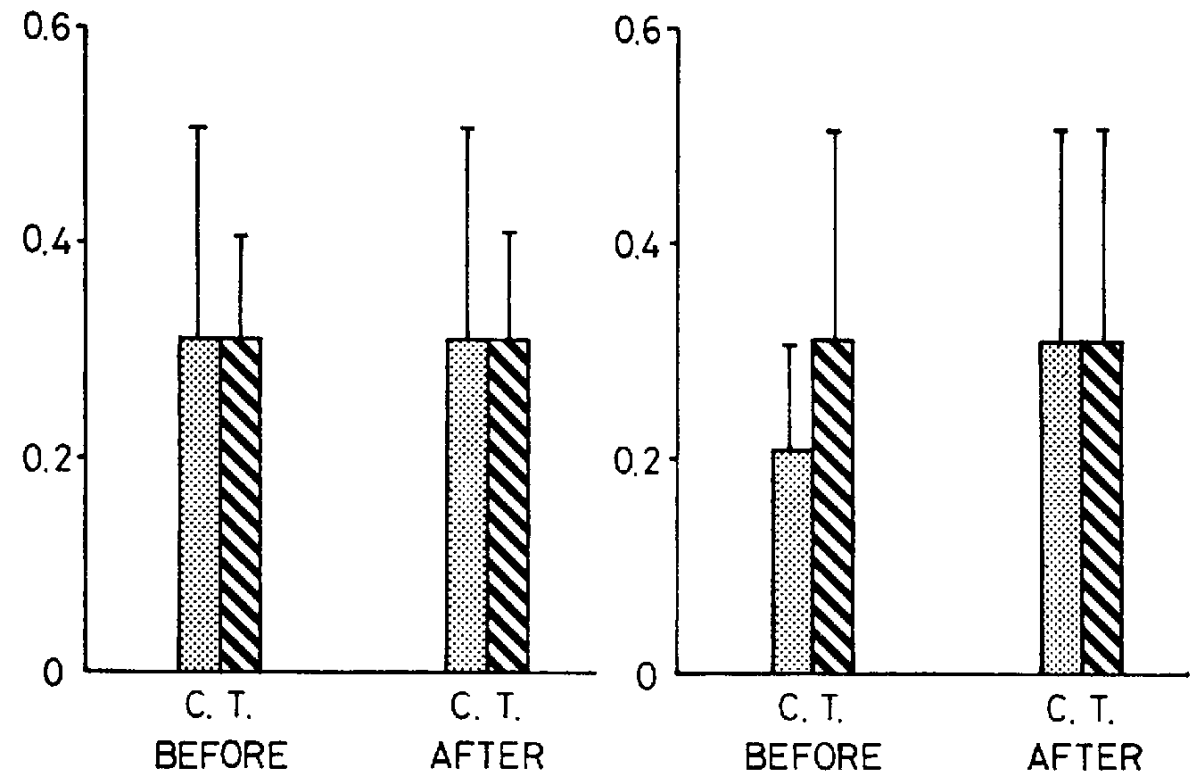

FIG. 3. Effect of theophylline on preening (left hand panel) and grooming measures (right hand panel) in the open field test.

Sessions before and after the treatment are plotted along the abscissa. The mean frequency of preening or grooming during testing is plotted along the ordinate on the left or right hand panel, respectively.

TABLE 1. Mean scores of the aggressivencss rating for theophylline and control rats.

\begin{tabular}{ccccc}
\hline \multirow{2}{*}{ Item } & \multicolumn{2}{c}{ Pre-treatment } & \multicolumn{2}{c}{ Post-treatment } \\
& Theophylline & Control & Theophylline & Control \\
Rating score & $0.8 \pm 0.3$ & $0.6 \pm 0.2$ & $-14.6 \pm 1.3^{* * *}$ & $2.6 \pm 0.6$ \\
\hline
\end{tabular}

Each point represents the mean of 12 determinations \pm S.E.

Significance of difference in respect to the control group : ***-p<.001

The resulting data of the open field test are depicted in Figures 1,2 and 3. Before the treatment, there was no statistical difference between the experimental and the control groups on each measure in open field testing. After day 17 of the treatment, the frequency of both rearing and defecation decreased more in the theophyllinized group than in the control group (rearing: $t=2.89$, $\mathrm{df}=21, \mathrm{p}<.05$; defecation: $\mathrm{t}=-4.86, \mathrm{df}=21, \mathrm{p}<.001$ ), while differences were not observed on the other measures including that of ambulation.

As shown in Table 1, the difference of rating scores in aggressiveness between the experimental and the control groups was not significant before the treatment, while the scores after the injection in the theophyllinized group increased more than those in the control group $(t=10.60, \mathrm{df}=21, \mathrm{p}<.001)$.

As for the reflexive fighting test, shown in Table 2, differences were not observed between the two groups over all measures before the treatment. On day 20 after the injection, $50 \%$ of the theophyllinized pairs reacted to an auditory stimulus $(\mathrm{p}<.01$ by Fisher 
TABLE 2. Mean frequency, latency and duration of fights for a pair of theophyllinized or control rats before and after the treatment in reflexive fighting test.

\begin{tabular}{|c|c|c|c|c|c|c|}
\hline \multirow[b]{2}{*}{ Procedures } & \multicolumn{2}{|c|}{ Adaptation period } & \multicolumn{2}{|c|}{ First shock period } & \multicolumn{2}{|c|}{ Second shock period } \\
\hline & $\begin{array}{l}\text { Reaction to } \\
\text { hand-clap } \\
(\%)\end{array}$ & $\begin{array}{l}\text { Fighting } \\
\text { duration } \\
\text { (sec) }\end{array}$ & $\begin{array}{l}\text { Fighting } \\
\text { frequency }\end{array}$ & $\begin{array}{l}\text { Fighting } \\
\text { duration } \\
\text { (sec) }\end{array}$ & $\begin{array}{l}\text { Latency to } \\
\text { fight } \\
\text { (sec) }\end{array}$ & $\begin{array}{l}\text { Fighting } \\
\text { duration } \\
\text { (sec) }\end{array}$ \\
\hline \multicolumn{7}{|l|}{ Before the treatment } \\
\hline Control pairs & 0 & 0 & $0.4 \pm 0.2$ & $3.9 \pm 0.7$ & $4.5 \pm 0.9$ & $21.0 \pm 2.1$ \\
\hline Theophyllinized pairs & 0 & 0 & $0.4 \pm 0.2$ & $3.8 \pm 0.7$ & $4.1 \pm 0.9$ & $18.8 \pm 1.9$ \\
\hline \multicolumn{7}{|l|}{ After the treatment } \\
\hline Control pairs & 0 & 0 & $0.3 \pm 0.2$ & $6.1 \pm 1.1$ & $4.3 \pm 0.9$ & $201.0 \pm 6.3$ \\
\hline Theophyllinized pairs & $50 \pm 3.1^{* *}$ & $14.5 \pm 1.7^{* * *}$ & $1.0 \pm 0.4^{*}$ & $271.0 \pm 8.1^{* *}$ & $0.7 \pm 0.3^{*}$ & $595.8 \pm 10.9^{*}$ \\
\hline
\end{tabular}

Each point represents the mean of 12 determinations \pm S.E.

Significance of difference in respect to control pairs : $*=\mathrm{p}<.05, * *=\mathrm{p}<.01, * * *=\mathrm{p}<.001$.

exact probability test) and continued to fight for 14.5 seconds out of 15 seconds in the adaptation period, while the saline control pairs showed no response, i.e. zero second $(U=$ $0, p<.001)$. The theophyllinized pairs took the fighting position more promptly, frequently and continuously than the control pairs both at the first (fighting frequency: $U=6$, $\mathrm{p}<.05$; fighting duration: $\mathrm{U}-2, \mathrm{p}<.01$ ) and the second shock periods (latency to fight: $\mathrm{U}=5, \mathrm{p}<.05$; fighting duration: $\mathrm{U}-7, \mathrm{p}<.05$ ). Only at the second shock period, however, fighting duration for the control pairs increased significantly after treatment as opposed to pre-treatment $(T=0, p<.05)$. On the dominancy test on day 20 , nine out of $12(75 \%)$ theophyllinized animals were dominant over control animals, while the control subjects did not dominate theophylline-treated partners $(\mathrm{p}<.0001$ by Fisher exact probability test).

\section{DISCUSSION}

The present results of the rating scores and the fighting test support the finding in a previous sludy (1) which demonstrated the production of affective aggression with the chronic treatment of theophylline, particularly from the points that $75 \%$ theophyllinized rats established dominancy against the control animals, and that fighting response was elicited by a hand-clap in 50\% theophyllinized pairs. Fighting duration in controls, though only at the second shock period, increased after treatment as opposed to pre-treatment. It is possible that the animals simply learned to fight in this repeated fighting situation. In the open field test of this experiment, frequency of defecation being a sensitive indicator of an emotional response $(5,6)$, decreased in the theophyllinized group as compared with the controls. This existing difference between two groups was not dependent on the restricted amount of fecal material as the result of prolonged food restriction, as the restriction had been equally carried out in both the control and the theophyllinized groups; and moreover, Broadhurst (5) demonstrated that defecation scores are independent of differences in the amount of fecal material available resulting from the food deprivation variable. Il is, therefore, reasonable to attribute this different defecation score to the 
emotionality between the two groups. This finding supports evidence that a negative correlation exists between aggressiveness and defecation in the open field test (7).

Acknowledgments: Thanks are due to Dr. I. Arthur Mirsky and Dr. Robert E. Miller of Laboratory of Clinical Science, University of Pittsburgh, U.S.A. for suggestions and a critical reading of the manuscript and Dr. Toshiyuki Yanase of the First Department of Internal Medicine, Kyushu University, Dr. Ken Fukamachi and Dr. Michio Ono of Hamanomachi Hospital, Fukuoka, for their interest and advice concerning the subject.

\section{REFERENCES}

1) Sakata, T. and Fuchimoto, H.: Japan. J. Pharmacol. 23, 781 (1973)

2) Whimbey, A.E. And Denenberg, V.H.: J. comp. physiol. Psychol. 63, 500 (1967)

3) AZuma, N.: Folia pharmacol. japon. 60, 259 (1964) (in Japanese)

4) Bernstein, H. A.id Moyer, K.E.: Brain Res. 20, 75 (1970)

5) Broadhurst, P.L.: Br. J. Psychol. 48, 1 (1957)

6) HaLl, C.S.: J. comp. Psychol. 22, 345 (1936)

7) Lagerspetz, K.M.J.: Aggressive Behaviour, Edited by Garatini, S. and Sigg, E.B., p. 77, Excerpta Medica Foundation, Amsterdam (1969) 